\title{
A proposed integration of the expert performance and individual differences approaches to the study of elite performance
}

\author{
Scott Barry Kaufman ${ }^{1,2 *}$ \\ 1 The Imagination Institute, Philadelphia, PA, USA \\ ${ }^{2}$ Positive Psychology Center, University of Pennsylvania, Philadelphia, PA, USA \\ *Correspondence: sbk@psych.upenn.edu
}

Edited by:

David Zachary Hambrick, Michigan State University, USA

Reviewed by:

Fernand Gobet, University of Liverpool, UK

Keywords: expertise, intelligence, motivation, individual differences, expert performance, inspiration, general cognitive ability

I recently had the pleasure of editing a volume of essays on the determinants of greatness (Kaufman, 2013a). A variety of perspectives were represented in the volume, including behavioral genetics, individual differences, and expert performance. The clearest conclusion from the volume was that the development of high achievement involves a complex interaction of many personal and environmental variables that feed off each other in nonlinear, mutually reinforcing, and nuanced ways, and that the most complete understanding of the development of elite performance can only be arrived through an integration of perspectives.

To help spur more integration, I suggest that cognitive psychologists who are studying deliberate practice and chunking, and individual differences researchers who are investigating cognitive ability and personality, focus more on common ground. I've noticed that the debate often ends up being "innate talent vs. deliberate practice” (see Ericsson et al., 2007; Ericsson, 2014), when that false dichotomy is detrimental to scientific progress (Gobet, 2013; Kaufman, 2013a). Deliberate practicedefined by Ericsson (2013) as "engagement with full concentration in a training activity designed to improve a particular aspect of performance with immediate feedback, [and] opportunities for gradual refinement by repetition and problem solving"-depends on many traits which vary in the general population, and which have a genetic basis. But that doesn't mean that heritable traits are necessarily "immutable constraints on the acquisition of various types of expert performance" (Ericsson, 2014).

Given our current state of scientific knowledge, I hope we can all agree that:

- There is no such thing as "innate talent." All skills require practice and support for their development (Kaufman, 2013b).

- The sheer number of hours engaged in practice is not as important as the quality of deliberate practice (Ericsson, 2013).

- There is nothing magical about $10,000 \mathrm{~h}$ of deliberate practice: the average hours of deliberate practice associated with expert performance varies by domain, and within domains, varies among individuals (Ericsson, 2013; Kaufman, 2013a).

- Deliberate practice does not explain all of the variation in elite performance (Ericsson, 2013; Hambrick et al., 2014).

- Other traits beyond deliberate practice are critical for the development of expert performance.

- Virtually all psychological traits are influenced by a complex, dynamic interplay of genetic and environmental factors (Johnson et al., 2009).

- Individual differences at any single moment of time don't necessarily constrain ultimate levels of performance, even though they may influence the rate of expertise acquisition.

Assuming researchers can agree on these seven basic principles, a fruitful research direction is the investigation of the manner in which individual differences influence (but not necessarily constrain) the development of expertise. One mode of operation is by influencing the efficiency of expertise acquisition, therefore speeding up the rate of acquisition. Ericsson (2013) acknowledges that the $10,000 \mathrm{~h}$ of practice he found among elite violinists at age 20 was just an average, with substantial variation around the mean. In fact, Simonton has found across the arts, sciences, and leadership, that those with the greatest lifetime productivity and highest levels of eminence required the least amount of time to acquire the requisite expertise (Simonton, 1991a,b, 1992, 1997, 1999).

General cognitive ability is one factor that can influence the efficiency of expertise acquisition. Individual differences researchers have spent over 100 years studying patterns of variation in cognitive ability (e.g., Carroll, 1993; Jensen, 1998). Brain imaging studies support the idea that people who do well on tests of cognitive ability use fewer brain resources to solve novel and complex problems (Haier et al., 1992; Neubauer and Fink, 2009; Van den Heuvel et al., 2009; Deary et al., 2010; Prabhakaran et al., 2011). Unfortunately, this literature (which emphasizes cognitive efficiency) is not well integrated with the research of cognitive psychologists who emphasize deliberate practice, chunking, and strategy use. However, I believe these various approaches are better suited for integration than it may seem at first blush.

Consider a set of studies conducted by Bor and colleagues, in which they 
found that chunking consistently activates the prefrontal-parietal brain network (Bor et al., 2004; Bor and Owen, 2007; Bor, 2012; Bor and Seth, 2012). Bor and Owen (2007) had participants memorize unfamiliar verbal and numerical double-digit sequences. The sequences were either randomly arranged (e.g., 31, 24, 89, 65)and therefore not conducive to the use of strategies—or structured (e.g., 57, 68, 79, 90) - which made them amenable to the use of chunking strategies. The prefrontalparietal brain network was consistently most active during the structured trials, even though the unstructured trials placed a higher demand on working memory, and were more difficult for participants to memorize.

The prefrontal-parietal network has also been heavily implicated on tests of working memory and general cognitive ability (Prabhakaran et al., 2000; Jung and Haier, 2007; Colom et al., 2009). The research of Bor and colleagues suggests that one of the primary functions of the prefrontal-parietal brain network is the conscious detection of patterns, which aids in the efficiency of learning. Indeed, Spearman (1904) argued that the best measure of general cognitive ability requires grasping relationships, inferring rules, noticing similarities and differences, and "educing" (Lating for "drawing out") the relevant relations in a complex pattern. Indeed, the Ravens Progressive Matrices test-which is strongly correlated with the general cognitive ability factor-appears to measure these skills (Conway et al., 2003). The Ravens test places a heavy burden on working memory because you must engage in fluid reasoning on the spot, with no external aids and often with strict time limits. However, those who have more efficient cognitive strategies for lessening the cognitive load will be at a distinct advantage in this testing environment.

Consistent with this idea, Nandagopal et al. (2010) had twins think aloud while they solved various tasks, including an associative learning task that is significantly correlated with general cognitive ability (see Kaufman et al., 2009). They found that performance on tests of cognitive ability were heavily influenced by the use of strategies, and differences in strategy use on an associative learning task (which was amenable to use of strategies) explained a significant amount of the genetic influences on performance.

Their study raises the intriguing suggestion that the heritability of general cognitive ability may be due, in part, to the ability to efficiently chunk information in working memory. Therefore, while Ericsson (2014) may be right that cognitive ability does not necessarily constrain the acquisition of expertise, it's still entirely possible that cognitive ability influences the efficiency and rate of expertise acquisition (especially when expertise acquisition draws heavily on general cognitive ability; 2014 special issue). Consistent with this, Meinz and Hambrick (2010) found that although deliberate practice accounted for $45.1 \%$ of the variation in piano sight-reading performance among expert pianists, working memory accounted for an additional $7.4 \%$ of the variance.

Of course, cognitive efficiency isn't the only way that individual differences can influence expertise acquisition. Another mode of operation is by sustaining the motivation to practice over an extended period of time. Ericsson et al. (1993) acknowledged this possibility when they say: "It is quite plausible, however, that heritable individual differences might influence processes related to motivation and the original enjoyment of the activities in the domain and, even more important, affect the inevitable differences in the capacity to engage in hard work (deliberate practice)" (p. 399). Even Arthur Jensen (one of the biggest proponents of general cognitive ability) once concluded that "some kind of motivational factor that sustains enormous and prolonged interest and practice in a particular skill probably plays a larger part in extremely exceptional performance than does psychometric $g$ or the speed of elementary information processes (Jensen, 1990, p. 259, italics added)."

I believe an overlooked characteristic that influences the motivation to engage in deliberate practice is inspiration (Kaufman, 2013b). When people become inspired, they usually are inspired to realize some future image of themselves (Torrance, 1983). It is the clarity of this vision, and the belief that the vision is attainable, that can propel a person from apathy to engagement, and sustain the energy to engage in deliberate practice over the long haul, despite obstacles and setbacks. Indeed, Todd Thrash, Andrew Elliot, and colleagues have conducted multiple studies showing that inspiration (measured both as a trait and a motivational state) is associated with an approach motivation, positive emotions, and an increase in creative productivity (Thrash and Elliot, 2003, 2004; Thrash et al., 2010).

In fact, in one of their studies (Thrash et al., 2010), inspiration not only predicted the creativity of writing samples in science and poetry, but also increased the efficiency of the writing samples (e.g., a larger number of typed words that were retained in the final product, and less time pausing and more time writing). This raises the intriguing idea that motivational characteristics may cause an increase in cognitive efficiency, which would ultimately increase the rate of expertise acquisition. I believe this is a promising area for future research.

These are just a few examples of how the cognitive psychology approach to expertise and the investigation of individual differences can be more tightly integrated. To conclude: while others have suggested the importance of computer modeling for integration (Gobet, 2013), I have argued here that other important contributors to scientific progress are accurate framing of the issues, standing on a common ground of assumptions, and investigating the influence of traits on the development of expertise.

\section{ACKNOWLEDGMENT}

Thanks to Zach Hambrick for his encouragement to submit this paper.

\section{REFERENCES}

(2014). Acquiring expertise: ability, practice, and other influences. Intelligence 45, 1-124 (special issue).

Bor, D. (2012). The Ravenous Brain: How the New Science of Consciousness Explains Our Insatiable Search for Meaning. New York, NY: Basic Books.

Bor, D., Cumming, C. N., Scott, E., and Owen, A. M. (2004). Prefrontal cortical isnvolvement in verbal encoding strategies. Eur. J. Neurosci. 18, 3365-3370. doi: 10.1111/j.1460-9568.2004. 03438.x

Bor, D., and Owen, A. M. (2007). A common prefrontal-parietal network for mnemonic and mathematical recoding strategies within working memory. Cereb. Cortex 17, 778-786. doi: 10.1093/cercor/bhk035

Bor, D., and Seth, A. K. (2012). Consciousness and the prefrontal parietal network: insights from 
attention, working memory, and chunking. Front. Psychol. 3:63. doi: 10.3389/fpsyg.2012.00063

Carroll, J. B. (1993). Human Cognitive Abilities. Cambridge: Cambridge University Press.

Colom, R., Haier, R. J., Head, K., Alvarez-Linera, J., Quiroga, M. A., Shih, P. C., et al. (2009). Gray matter correlates of fluid, crystallized, and spatial intelligence: testing the P-FIT model. Intelligence 37, 124-135. doi: 10.1016/j.intell.2008.07.007

Conway, A. R. A., Kane, M. J., and Engle, R. W. (2003). Working memory capacity and its relation to general intelligence. Trends Cogn. Sci. 7, 547-552. doi: 10.1016/j.tics.2003.10.005

Deary, I. J., Penke, L., and Johnson, W. (2010). The neuroscience of human intelligence differences. Nat. Rev. Neurosci. 11, 201-211. doi: $10.1038 / \mathrm{nrn} 2793$

Ericsson, K. A. (2013). Training history, deliberate practice and elite sports performance: an analysis in response to Tucker and Collins review-what makes champions? Br. J. Sports Med. 47, 533-535. doi: 10.1136/bjsports-2012-091767

Ericsson, K. A. (2014). Why expert performance is special and cannot be extrapolated from studies of performance in the general population: a response to criticisms. Intelligence $45,81-103$. doi: 10.1016/j.intell.2013.12.001

Ericsson, K. A., Krampe, R. T., and Tesch-Römer, C. (1993). The role of deliberate practice in the acquisition of expert performance. Psychol. Rev. 100, 363-406. doi: 10.1037/0033-295X. 100.3.363

Ericsson, K. A., Roring, R. W., and Nandagopal, K. (2007). Giftedness and evidence for reproducibly superior performance: an account based on the expert performance framework. High Abil. Stud. 18, 3-56. doi: 10.1080/13598130701350593

Gobet, F. (2013). Expertise vs. talent. Talent Dev. Excellence 5, 59-70. Available online at: http:// www.iratde.org/journal/issues/112-issue-20131

Haier, R. J., Siegel, B., Tang, C., Abel, L., and Buschbaum, M. S. (1992). Intelligence and changes in regional cerebral glucose metabolic-rate following learning. Intelligence 16, 425-426. doi: 10.1016/0160-2896(92)90018-M

Hambrick, D. Z., Oswald, F. L., Altmann, E. M., Meinz, E. J., Gobet, F., and Campitelli, G. (2014). Deliberate practice: is that all it takes to become an expert? Intelligence 45, 34-45. doi: 10.1016/j.intell. 2013.04.001

Jensen, A. (1998). The g Factor. New York, NY: Praeger.

Jensen, A. R. (1990). Speed of information processing in a calculating prodigy. Intelligence 14, 259-274. doi: 10.1016/0160-2896(90)90019-P
Johnson, W., Turkheimer, E., Gottesman, I. I., and Bouchard, T. J. Jr. (2009). Beyond heritability: twin studies in behavioral research. Curr. Dir. Psychol. Sci. 18, 217-220. doi: 10.1111/j.14678721.2009.01639.x

Jung, R. E., and Haier, R. J. (2007). The parieto-frontal integration theory (P-FIT) of intelligence: converging neuroimaging evidence. Behav. Brain Sci. 30, 135-154. doi: 10.1017/S0140525X07001185

Kaufman, S. B. (2013a). The Complex of Greatness: Beyond Talent or Practice. New York, NY: Oxford University Press.

Kaufman, S. B. (2013b). Ungifted: Intelligence Redefined. New York, NY: Basic Books.

Kaufman, S. B., DeYoung, C. G., Gray, J. R., Brown, J., and Mackintosh, N. (2009). Associative learning predicts intelligence above and beyond working memory and processing speed. Intelligence 37, 374-382. doi: 10.1016/j.intell.2009. 03.004

Meinz, E. J., and Hambrick, D. Z. (2010). Deliberate practice is necessary but not sufficient to explain individual differences in piano sightreading skill. Psychol. Sci. 21, 914-919. doi: 10.1177/0956797610373933

Nandagopal, K., Roring, R., Ericsson, K. A., and Taylor, J. (2010). Strategies may mediate heritable aspects of memory performance: a twin study. Cogn. Behav. Neurol. 23, 224-230. doi: 10.1097/ WNN.0b013e3181e07d29

Neubauer, A. C., and Fink, A. (2009). Intelligence and neural efficiency. Neurosci. Biobehav. Rev. 33 , 1004-1023. doi: 10.1016/j.neubiorev.2009.04.001

Prabhakaran, V., Narayanan, K., Zhao, Z., and Gabrieli, J. D. (2000). Integration of diverse information in working memory within the frontal lobe. Nat. Neurosci. 3, 85-90. doi: 10.1038/ 71156

Prabhakaran, V., Rypma, B., Narayanan, N. S., Meier T. B., Austin, B. P., Nair, V. A., et al. (2011). Capacity-speed relationships in prefrontal cortex. PLOS ONE 6:e27504. doi: 10.1371/journal.pone. 0027504

Simonton, D. K. (1991a). Career landmarks in science: individual differences and interdisciplinary contrasts. Dev. Psychol. 27, 119-130. doi: 10.1037/0012-1649.27.1.119

Simonton, D. K. (1991b). Emergence and realization of genius: the lives and works of 120 classical composers. J. Pers. Soc. Psychol. 61, 829-840.

Simonton, D. K. (1992). Leaders of American psychology, 1879-1967: career development, creative output, and professional achievement. J. Pers. Soc. Psychol. 62, 5-17. doi: 10.1037/0022-3514.62.1.5
Simonton, D. K. (1997). Creative productivity: a predictive and explanatory model of career trajectories and landmarks. Psychol. Rev. 104, 66-89. doi: 10.1037/0033-295X.104.1.66

Simonton, D. K. (1999). Talent and its development: an emergenic and epigenetic model. Psychol. Rev. 106, 435-457. doi: 10.1037/0033-295X. 106.3.435

Spearman, C. (1904). General intelligence: objectively determined and measured. Am. J. Psychol. 15, 201-293. doi: 10.2307/1412107

Thrash, T. M., and Elliot, A. J. (2003). Inspiration as a psychological construct. J. Pers. Soc. Psychol. 84, 871-889. doi: 10.1037/0022-3514.84.4.871

Thrash, T. M., and Elliot, A. J. (2004). Inspiration: core characteristics, component processes, antecedents, and function. J. Pers. Soc. Psychol. 87, 957-973. doi: 10.1037/0022-3514.87.6.957

Thrash, T. M., Maruskin, L. A., Cassidy, S. E., Fryer, J. W., and Ryan, R. M. (2010). Meditating between the muse and the masses: inspiration and the actualization of creative ideas. J. Pers. Soc. Psychol. 98 , 469-487. doi: 10.1037/a0017907

Torrance, E. P. (1983). The importance of falling in love with "something." Creativ. Child Adult Q. 8 , 72-78.

Van den Heuvel, M. P., Stam, C. J., Kahn, R. S., and Hulshoff Pol, H. E. (2009). Efficiency of functional brain networks and intellectual performance. J. Neurosci. 29, 7619-7624. doi: 10.1523/ JNEUROSCI.1443-09.2009

Conflict of Interest Statement: The author declares that the research was conducted in the absence of any commercial or financial relationships that could be construed as a potential conflict of interest.

Received: 31 May 2014; accepted: 19 June 2014; published online: 09 July 2014.

Citation: Kaufman SB (2014) A proposed integration of the expert performance and individual differences approaches to the study of elite performance. Front. Psychol. 5:707. doi: 10.3389/fpsyg.2014.00707

This article was submitted to Cognition, a section of the journal Frontiers in Psychology.

Copyright (c) 2014 Kaufman. This is an open-access article distributed under the terms of the Creative Commons Attribution License (CC BY). The use, distribution or reproduction in other forums is permitted, provided the original author(s) or licensor are credited and that the original publication in this journal is cited, in accordance with accepted academic practice. No use, distribution or reproduction is permitted which does not comply with these terms. 